\title{
Is biofilm removal properly assessed? Comparison of different quantification methods in a 96-well plate system
}

\author{
Philipp Stiefel $^{1}$ - Urs Rosenberg ${ }^{2} \cdot$ Jana Schneider $^{1} \cdot$ Stefan Mauerhofer $^{2}$. \\ Katharina Maniura-Weber ${ }^{1} \cdot$ Qun $^{\text {Ren }}{ }^{1}$
}

Received: 10 September 2015 / Revised: 10 February 2016 / Accepted: 12 February 2016 / Published online: 29 February 2016

(C) The Author(s) 2016. This article is published with open access at Springerlink.com

\begin{abstract}
Various methods have been reported to quantify total biofilm or different components of biofilm; however, these methods are often confusedly used, leading to discrepancies and misleading results. In this study, different methods for quantification of biofilm, including those for total biomass, total amount of bacterial cells, viable cell number, and amount of extracellular polymeric substances, were systematically compared in microtiter plates. To evaluate which method is suitable for assessment of biofilm removal and for bacterial killing, biofilm samples were treated with various cleaners possessing removing and/or killing capacities. It was found that most of the methods tested in this study in general exhibited high reproducibility and repeatability. Crystal Violet staining was a simple but reliable method for total biomass quantification. Total bacteria cell numbers could be reliably quantified by the fluorescent DNA-binding dye Acridine Orange. Viable cells could be quantified by either an ATPbased assay or a proliferation assay. Both of these viability methods showed a broad detection range and led to precise measurement. For quantification of proteins in the biofilm, staining with fluorescein isothiocyanate was most suitable. Furthermore, it was revealed that a combination of different
\end{abstract}

Electronic supplementary material The online version of this article (doi:10.1007/s00253-016-7396-9) contains supplementary material, which is available to authorized users.

Qun Ren

qun.ren@empa.ch

1 Laboratory for Biointerfaces, Empa, Swiss Federal Laboratories for Materials Science and Technology, Lerchenfeldstrasse 5, CH-9014 St. Gallen, Switzerland

2 Borer Chemie AG, Gewerbestrasse 13, 4528 Zuchwil, Switzerland methods is required to determine if a cleaner kills or removes biofilm.

Keywords Biofilm quantification · Biofilm removal · Microtiter plate $\cdot$ Enzymatic cleaner $\cdot$ Method comparison

\section{Introduction}

Under natural conditions, most bacteria occur in the form of a biofilm. They adhere to surfaces embedded in a self-produced layer of extracellular polymeric substances (EPS) (Flemming and Wingender 2001; Sutherland 2001). The EPS protect bacteria against environmental influences such as UV irradiation, antibiotics, and disinfection, which make them much more tolerant to these influences compared to planktonic bacterial cells (Cochran et al. 2000; Elasri and Miller 1999; Stewart and Costerton 2001). The unique structure of biofilm makes it difficult to be removed. Particular precautions have to be taken in the field of health care. Hospital-acquired infections, which often arise from incomplete removal of biofilm from instruments and device surfaces, account for a substantial part of health problems and costs (Zimlichman et al. 2013).

An example is the transfer of pathogens on flexible endoscopes. Endoscopes get in contact with different body fluids and provide ideal surfaces for biofilm formation. Viable bacteria were isolated from many endoscope channels even after the cleaning and disinfection process (Alfa et al. 1999; Chiu et al. 2012; Kovaleva et al. 2013; Pajkos et al. 2004). Thus, biofilm cleaners need to be carefully developed and evaluated for their performance. Different methods have been reported for biofilm analysis. Viable bacteria can be detected by monitoring their metabolic activity (e.g., ATP by BacTiter-Glo ${ }^{\mathrm{TM}}$ assay (Berney et al. 2008) or respiratory electrons by tetrazolium salt (Hatzinger et al. 2003)), membrane integrity (e.g., 
live/dead staining by SYTO9 and propidium iodide (Tawakoli et al. 2013)), or ability to grow (e.g., colony forming units or time to regrow to a specific turbidity (Alt et al. 2004)). The total amount of live and dead bacteria can be measured using DNA-binding dyes (e.g., DAPI, Hoechst, SYTO9 or Acridine Orange (Peeters et al. 2008; Palestrant et al. 2004)) or qPCR. Also, the EPS compounds can be visualized and quantified. Proteins can be stained by specific dyes (e.g., SYPRO Ruby, CBQCA, or NanoOrange) or detected by specific reactions (e.g., Lowry method). The same is possible for polysaccharides which can, for example, be stained by fluorescently labeled lectins (e.g., ConA-FITC (Chen et al. 2007) binds $\alpha$ D-mannopyranosyl and $\alpha$-D-glucopyranosyl residues such as in amylopectin and dextran) and other dyes (e.g., Calcofluor White (Chen et al. 2007) binds $\beta(1 \rightarrow 4)$ linked D-glucose or derivatives such as cellulose and chitin) or detected by the phenol sulfuric acid method (Dubois et al. 1951). Fluorescein isothiocyanate (FITC) is also supposed to label proteins by reaction of the isothiocyanate group with primary and secondary amine groups to form a covalent bonding (Chen et al. 2007). Many of these methods are not yet described for biofilm quantification in a microtiter plate screening system. Simpler staining methods such as Crystal Violet (O'Toole 2011; Stepanovic et al. 2000) and Safranin Red (Patterson et al. 2010) which target total biomass were more frequently used. These dyes bind to negative charges and therefore target many different molecules of bacteria and EPS. An advantage of these methods is the simplicity and the direct optical visualization. However, the question remains open how quantitative and reliable these methods are in comparison to each other. Advantages and disadvantages of different methods were discussed (Pantanella et al. 2013), but experimental data were rarely used to support the statements (Peeters et al. 2008). Furthermore, only few quantification methods were compared for biofilm removal studies (Pitts et al. 2003). Especially, when biofilm removal or disinfection is concerned, little is discussed about which method is suitable for which purpose and what the detection limits are. Dependent on the used method, the readout will vary. If a cleaner kills the bacteria rather than removes them, the outcome for the efficiency will differ if a quantification method is selected to determine total biofilm or measure bacterial viability. In reported studies, conclusions for cleaning efficiency were often drawn based on detection of viable cells and not on actual biofilm removal (Hadi et al. 2010; Vickery et al. 2004). Thus, there is a need to conduct the experiments under the same conditions and compare different methods systematically.

In this study, biofilm formed in microplates and cleaners having biofilm-removing and/or bacteria-killing ability were used to investigate different biofilm quantification methods in 96-well plates. These include methods to determine total biomass, total bacteria, viable bacteria, and EPS including proteins and polysaccharides. As model organisms, the clinically relevant Gram-negative Pseudomonas aeruginosa and Gram-positive Staphylococcus aureus were employed (Pendleton et al. 2013). The cleaning efficiency of a novel enzymatic cleaner was compared with that of five commercial products. The advantages and disadvantages of the different methods are elaborated in detail in this report. The results and findings obtained here not only are scientifically interesting but also more importantly will allow correct assessment and monitoring of medical and environmental products, e.g., endoscope cleaners and disinfectants, for their efficacy in biofilm removal and/or killing bacterial cells.

\section{Materials and methods}

\section{Chemicals and reagents}

Chemicals and reagents used for bacteria growth, cleaner formulation, and biofilm detection were purchased from SigmaAldrich (Switzerland) if not mentioned elsewise.

\section{Bacterial strains and cultivation conditions}

Bacterial strains were obtained from the Leibniz Institute DSMZ - German Collection of Microorganisms and Cell Cultures. Pseudomonas aeruginosa (DSM No. 1117) and Staphylococcus aureus (DSM No. 20231) were grown on tryptic soy agar at $37{ }^{\circ} \mathrm{C}$. Liquid cultures were grown in $30 \%$ tryptic soy broth (TSB, $9 \mathrm{~g} / 1$ which corresponds to $30 \%$ of recommended concentration) supplemented with $2.5 \mathrm{~g} / \mathrm{l}$ glucose at $37^{\circ} \mathrm{C}$ and $160 \mathrm{rpm}$.

\section{Biofilm formation}

Overnight cultures were diluted to $\mathrm{OD}_{600 \mathrm{~nm}}$ of 0.2 in $30 \%$ TSB supplemented with $2.5 \mathrm{~g} / \mathrm{l}$ glucose. Two hundred microliters of bacteria suspension per well were added to transparent (for absorbance), black (for fluorescence), or white (for luminescence) flat-bottom polystyrene 96 -well plates (BRANDplates ${ }^{\circledR}$ pureGrade ${ }^{\mathrm{TM}}$ ). Samples were arranged as indicated in Figure S1a. To determine the staining background, two rows of the microplate were filled with medium without bacteria. One column was left empty (no medium and bacteria) during biofilm formation and later was also washed and treated with $0.9 \% \mathrm{NaCl}$ solution to determine the staining background signals of the plate. Plates were incubated for $24 \mathrm{~h}$ at $33{ }^{\circ} \mathrm{C}$ and $40 \mathrm{rpm}$. The biofilm formed in the wells was washed once with $350 \mu \mathrm{l} 0.9 \% \mathrm{NaCl}$ solution before the treatment with cleaner. 


\section{Cleaner treatment}

In this study, five commercially available high-end endoscope cleaners (cleaners A-E) and one newly developed cleaner $\mathrm{X}$ were chosen, all of which contain enzymes and/or claim to be efficient in removing biofilm (Table 1).

All cleaners were used at a concentration of $1 \%$ (as recommended by the manufacturers) in freshly prepared water of standardized hardness (WSH) containing 1.25 $\mathrm{mM} \mathrm{MgCl} 2,2.5 \mathrm{mM} \mathrm{CaCl}_{2}$, and $3.33 \mathrm{mM} \mathrm{NaHCO}_{3}$ in deionized water. The samples were arranged as described in Figure S1b. Each column (six wells with bacteria, two wells with medium only) was treated with a different cleaner. A mixture of $1 \%$ SDS, $1 \%$ EDTA, $1 \%$ $\mathrm{NaOH}$, and $0.1 \% \mathrm{NaClO}$ was used as the positive control, and $0.9 \% \mathrm{NaCl}$ solution was used as the negative control. Treatment was done with $250 \mu$ l cleaner per well for $40 \mathrm{~min}$ at $25^{\circ} \mathrm{C}$. Two columns for background control were also treated with $0.9 \% \mathrm{NaCl}$ solution: one to determine the background of cells without staining and the other one for the staining background of the plate (the empty one without bacteria and medium). Before applying the different detection methods, the wells were washed three times with $350 \mu \mathrm{l} 0.9 \% \mathrm{NaCl}$ solution to remove the cleaner and dislodged debris. Finally, all liquid was removed before immediately applying the specific quantification method.

\section{Biofilm quantification}

After the application of the quantification methods described below, absorbance, fluorescence, or luminescence were measured with a Synergy HT Multi-Detection Microplate Reader (BioTek $\left.{ }^{\circledR}\right)$.

\section{Total Biomass}

The classical dyes such as Crystal Violet and Safranin Red bind to negatively charged molecules and can be used to stain and quantify total biomass comprising bacteria and EPS.

Crystal Violet staining Two hundred fifty microliters of $0.5 \%$ Crystal Violet (CV) was added per well (except one column which was used to determine the background of the cells and medium). The plate was incubated for $30 \mathrm{~min}$ at $25^{\circ} \mathrm{C}$ before removing the staining solution, and then washed three times with $350 \mu \mathrm{l} 0.9 \% \mathrm{NaCl}$ solution. After removing the washing solution, $100 \mu 196 \%$ EtOH was added per well to dissolve the biofilm-bound $\mathrm{CV}$ by gently knocking the plate. Absorbance was measured at $595 \mathrm{~nm}$.

Safranin Red staining Safranin Red staining was similar to CV staining, except that $0.5 \%$ Safranin Red was used and absorbance was measured at $535 \mathrm{~nm}$.

Congo Red staining Congo Red staining was similar to $\mathrm{CV}$ staining, except that $0.5 \%$ Congo Red was used and absorbance was measured at $500 \mathrm{~nm}$.

\section{Total amount of bacterial cells}

Dyes binding to DNA and RNA such as SYTO9 and Acridine Orange can be used to quantify both live and dead bacterial cells and provide an insight into the total amount of bacterial cells in the biofilm.

SYTO9 staining One hundred microliters of $2.5 \mu \mathrm{M}$ SYTO9 (Life Technologies) in $0.9 \% \mathrm{NaCl}$ solution was added per well (except one column which was used to determine the background of the cells and medium). The plate was closed

Table 1 Summary of biofilm removal capacity of the cleaners tested in this study

\begin{tabular}{|c|c|c|c|c|c|c|c|c|c|c|}
\hline \multirow[t]{2}{*}{ Cleaner } & \multirow[t]{2}{*}{$\begin{array}{l}\text { Enzymes supplemented } \\
\text { in the cleaners }\end{array}$} & \multirow[t]{2}{*}{ Claim for biofilm removal } & \multicolumn{2}{|c|}{ Biomass } & \multicolumn{2}{|c|}{$\begin{array}{l}\text { Amount of } \\
\text { bacteria }\end{array}$} & \multicolumn{2}{|c|}{$\begin{array}{l}\text { Amount of viable } \\
\text { bacteria }\end{array}$} & \multicolumn{2}{|c|}{$\begin{array}{l}\text { Amount of } \\
\text { EPS }\end{array}$} \\
\hline & & & P.a. & S.a. & P.a. & S.a. & P.a. & S.a. & P.a. & S.a. \\
\hline A & Protease, lipase, amylase & Yes & ++ & +++ & ++ & +++ & +++ & ++ & ++ & +++ \\
\hline $\mathrm{B}$ & Protease, amylase, cellulase & Yes & +++ & +++ & +++ & +++ & +++ & ++ & +++ & +++ \\
\hline $\mathrm{C}$ & Protease, lipase, amylase & None & ++ & + & 0 & 0 & +++ & +++ & 0 & 0 \\
\hline $\mathrm{D}$ & $\begin{array}{l}\text { Protease, lipase, amylase, cellulase, } \\
\text { mannanase }\end{array}$ & Yes & 0 & ++ & 0 & ++ & + & +++ & 0 & +++ \\
\hline $\mathrm{E}$ & None & Yes & + & 0 & 0 & 0 & ++ & +++ & 0 & ++ \\
\hline $\mathrm{X}$ & 4 enzymes & Yes & +++ & +++ & +++ & +++ & +++ & +++ & +++ & +++ \\
\hline
\end{tabular}

P.a., Pseudomonas aeruginosa; S.a., Staphylococcus aureus; +++ , strong ( $>80 \%$ in average of the used methods or $>90 \%$ in one of the methods); ++, medium ( $>50 \%$ in average, but none $>90 \%$ ); +, weak ( $25-50 \%$ in average); and 0 , no biofilm reduction ( $<25 \%$ in average). Those terms were applied to all methods, except for the viability of S.a. where the threshold for +++ was set to $99 \%$ due to strong reduction of all cleaners. More details on percent reduction of individual methods are summarized in Table S1 
with sealing aluminum foil (AlumaSeal IITM, Carl Roth) before vortexing for $10 \mathrm{~min}$ to detach biofilm and incubated for additional $5 \mathrm{~min}$. Fluorescence intensity was measured using excitation filter $485 / 20 \mathrm{~nm}$ and emission filter $528 / 20 \mathrm{~nm}$ (gain 70).

Acridine Orange staining Acridine Orange solution (2\% in $\mathrm{H}_{2} \mathrm{O}$ ) was diluted 1:100 in Walpole's buffer $(27.2 \mathrm{~g} / 1$ sodium acetate trihydrate, adjusted to $\mathrm{pH} 4$ with glacial acetic acid). Two hundred fifty microliters of the diluted Acridine Orange was added per well. After $15 \mathrm{~min}$ incubation in the dark, the staining solution was removed and the plate was washed three times with $350 \mu \mathrm{l} 0.9 \% \mathrm{NaCl}$ solution. After removing the washing solution, $100 \mu \mathrm{l} 0.9 \% \mathrm{NaCl}$ solution was added and the plate was closed with sealing aluminum foil before vortexing for $10 \mathrm{~min}$. Fluorescence intensity using excitation filter $485 / 20 \mathrm{~nm}$ and emission filter $528 / 20 \mathrm{~nm}$ (gain 50) was measured.

\section{Amount of living bacterial cells}

Methods which measure typical parameters of living bacteria such as metabolic activity, membrane integrity, or proliferation can be used to specifically quantify these bacterial cells.

BacTiter-Glo assay One hundred microliters of TSB was added to each well, and the plate was closed with sealing aluminum foil. The plate was vortexed for $10 \mathrm{~min}$ to detach the bacteria. One hundred microliters of BacTiter-Glo reagent (BacTiter-Glo ${ }^{\mathrm{TM}}$ Microbial Cell Viability Assay, Promega) prepared according to the manufacturer's instruction was added per well. The plates were incubated for $5 \mathrm{~min}$ in the dark on an orbital shaker. The luminescence intensity was measured with gain 135 for $1 \mathrm{~s}$ per well.

Turbidity threshold method Two hundred fifty microliters of $30 \%$ TSB ( $9 \mathrm{~g} / \mathrm{l})$ was added per well after cleaner treatment, and the plate was closed with a sealing transparent foil (Breathe-Easy, Carl Roth). The plate was incubated in the microplate reader at $33{ }^{\circ} \mathrm{C}$ with medium shaking $(18 \mathrm{~Hz}-$ the preset value of the instrument). Optical density at $600 \mathrm{~nm}$ was measured every $30 \mathrm{~min}$ for $24 \mathrm{~h}$. A dilution series of a bacterial culture enabled a correlation between cell numbers and time needed to reach a desired optical density (OD).

Tetrazolium salt assay Two hundred microliters of $30 \%$ TSB containing $0.5 \mathrm{mg} / \mathrm{ml}$ 2-(4-iodophenyl)-3-(4-nitrophenyl)-5-phenyl-2H-tetrazolium chloride (INT) was added to each well. The plate was incubated for $2 \mathrm{~h}$ at $33{ }^{\circ} \mathrm{C}$ with shaking at $40 \mathrm{rpm}$. The medium was removed, and $200 \mathrm{ml}$ dimethyl sulfoxide (DMSO) was added to dissolve the dye from the biofilm by knocking the plate carefully. Absorbance was measured at $470 \mathrm{~nm}$.
SYTO9/PI staining Continuing from SYTO9 staining described above, $100 \mu \mathrm{l}$ of $15 \mu \mathrm{M}$ propidium iodide in $0.9 \%$ $\mathrm{NaCl}$ solution was added. After 15 min incubation, fluorescence intensities using excitation filter 485/20 nm and emission filters 528/20 and 645/20 nm (gain 70) were measured.

\section{Biofilm EPS - amount of proteins}

FITC staining Two hundred fifty microliters of FITC solution $\left(20 \mu \mathrm{g} / \mathrm{ml}\right.$ fluorescein isothiocyanate in $\mathrm{ddH}_{2} \mathrm{O}$ prepared from $10 \mathrm{mg} / \mathrm{ml}$ stock in EtOH) was added to each well. After 30 min incubation in the dark, the staining solution was removed and the plate was washed twice with $350 \mu \mathrm{l} 0.9 \%$ $\mathrm{NaCl}$ solution. After removing the washing solution, $100 \mu \mathrm{l}$ $\mathrm{ddH}_{2} \mathrm{O}$ was added and the plate was closed with sealing aluminum foil before vortexing for $10 \mathrm{~min}$. Fluorescence intensity using excitation filter $485 / 20 \mathrm{~nm}$ and emission filter 528 / $20 \mathrm{~nm}$ (gain 70) was measured.

SYPRO Ruby staining SYPRO Ruby staining is similar to FITC staining, except that undiluted SYPRO Ruby solution (FilmTracer ${ }^{\mathrm{TM}}$ SYPRO $^{\circledR}$ Ruby Biofilm Matrix Stain, Life Technologies) was used for $15 \mathrm{~min}$ and fluorescence intensity was measured using excitation filter $460 / 40 \mathrm{~nm}$ and emission filter 645/40 nm (gain 80).

BCA/NanoOrange/CBQCA assays NanoOrange ${ }^{\circledR}$ Protein Quantitation Kit (Life Technologies), CBQCA Protein Quantitation Kit (Life Technologies), and Micro BCA ${ }^{\mathrm{TM}}$ Protein Assay Kit (Life Technologies) were performed according to manufacturers' instructions.

Lowry assay Two hundred fifty microliters of complexforming reagent (100:1:1 (v:v:v) mixture of $2 \%$ sodium carbonate, $1 \%$ copper(II) sulfate pentahydrate, and $2 \%$ sodium potassium tartrate tetrahydrate in $\mathrm{ddH}_{2} \mathrm{O}$ ) was added per well. The plate was incubated for $10 \mathrm{~min}$ at $25^{\circ} \mathrm{C}$. Fifty microliters of Folin \& Ciocalteu's phenol reagent was added. The plate was incubated for $30 \mathrm{~min}$ at $25^{\circ} \mathrm{C}$ before measuring absorbance at 540,650 , and $750 \mathrm{~nm}$.

\section{Biofilm EPS - amount of polysaccharides}

Calcofluor White staining Two hundred fifty microliters of Calcofluor White solution $\left(1 \mathrm{mg} / \mathrm{ml}\right.$ in $\left.\mathrm{dH}_{2} 0\right)$ was added per well and incubated for $15 \mathrm{~min}$ in the dark. The staining solution was removed, and the plate was washed twice with $350 \mu \mathrm{l}$ $0.9 \% \mathrm{NaCl}$ solution. After removing the washing solution, $200 \mu 196 \%$ EtOH was added per well to dissolve the biofilmbound Calcofluor White by gently knocking the plate. Fluorescence intensity using excitation filter $360 / 40 \mathrm{~nm}$ and emission filter 460/40 nm (gain 80) was measured. 
ConA-FITC staining Two hundred fifty microliters of $50 \mu \mathrm{g} / \mathrm{ml}$ ConA-FITC was added per well (diluted in $0.9 \%$ $\mathrm{NaCl}$ from $5 \mathrm{mg} / \mathrm{ml}$ stock in $0.1 \mathrm{M} \mathrm{NaHCO}_{3}$ ). After $15 \mathrm{~min}$ incubation in the dark, the staining solution was removed and the plate was washed twice with $350 \mu \mathrm{l} 0.9 \% \mathrm{NaCl}$ solution. After removing the washing solution, $100 \mu \mathrm{l} 0.9 \% \mathrm{NaCl}$ solution was added and the plate was closed with sealing aluminum foil before vortexing for $10 \mathrm{~min}$. Fluorescence intensity using excitation filter $485 / 20 \mathrm{~nm}$ and emission filter $528 / 20 \mathrm{~nm}$ (gain 80 ) was measured.

\section{Statistical analysis}

For each sample, the biofilm value was calculated by subtracting the mean value of the two wells with only medium from the arithmetic mean of six wells with biofilm. Sample standard deviations were calculated from the values of the six similarly treated wells. The statistical significance was determined for each data set using the unpaired, parametric, two-tailed Student's $t$ test. The value of the negative control $(0.9 \% \mathrm{NaCl}$ treated $)$ was set to $100 \%$ and the other values calculated accordingly. Three independent experiments with six repeats per condition in each experiment were performed for each detection method. Individual repeats displayed the same trend for all detection methods.

In this study a minimal reliable signal detected is defined using the IUPAC definition (http://goldbook.iupac.org/ L03540.html, IUPAC Compendium of Chemical Terminology - the Gold Book) to enable clear discrimination from background noise: the signal should be larger than the background signal by three times the standard deviation of the background. Maximal detectable reduction (MDR) values were calculated using the following formula:

$$
\begin{aligned}
\operatorname{MDR}[\%] & =100-\frac{\mathrm{MS}-\mathrm{BG}}{\mathrm{SNC}-\mathrm{BG}} \times 100 \\
& =100-\frac{3 * \mathrm{SD}}{\mathrm{SNC}-\mathrm{BG}} \times 100
\end{aligned}
$$

BG, background signal of stained wells which did not contain bacteria and medium $\mathrm{SD}$, standard deviation of the $\mathrm{BG}$ $\mathrm{MS}$, minimal reliable signal $(=\mathrm{BG}+3 * \mathrm{SD})$ $\mathrm{SNC}$, signal of negative control wells containing bacteria treated with $0.9 \% \mathrm{NaCl}$ solution instead of a cleaner

\section{Results}

\section{Biofilm formation and treatment}

Different conditions such as incubation temperature and duration were investigated for biofilm formation in 96-well plates.
It was found that incubation at $33{ }^{\circ} \mathrm{C}$ and $40 \mathrm{rpm}$ for $24 \mathrm{~h}$ was sufficient to obtain an adequate amount of biofilm for subsequent quantification. Prolonged incubation for $48 \mathrm{~h}$ and/or incubation at $37{ }^{\circ} \mathrm{C}$ did not lead to a significantly higher amount of biofilm (less than $10 \%$ in average). It was observed that $P$. aeruginosa formed the biofilm mainly at the liquid/air interface on the walls (Fig. S2a), whereas the S. aureus biofilm mainly adhered to the bottom and in the corners (Fig. S2b). This observation has been reported previously (O'Toole 2011). However, the different locations of biofilm should not influence the cleaning process as static condition was used and the biofilm was completely covered with the cleaner. Room temperature $\left(25^{\circ} \mathrm{C}\right)$ was selected for biofilm treatment with cleaners as this temperature is most often used for manually applied cleaning solutions. Incubation for $40 \mathrm{~min}$ was chosen for treatment as it was found to give reproducible results.

\section{Detection methods}

Biofilm in 96-well plates treated with different solutions (see "Materials and methods") was used to investigate the suitability and detection limits of various biofilm detection methods. The maximal detectable reduction (MDR) was used to reflect the sensitivity and the detection range of a method as described in "Materials and methods."

\section{Total biomass}

Without cleaner treatment (negative control), Crystal Violet staining resulted in an absolute absorbance value of 1.0 for P. aeruginosa and 0.3 for $S$. aureus, which can be easily and reliably detected (Fig. 1a, b). The standard deviations were generally less than $5 \%$. However, a relatively high amount of biomass was required to allow distinction from the background. The staining background of the plain plate had approximately a signal of 0.05 (Table 1). This allows reliable detection of up to $98.7 \%$ reduction for $P$. aeruginosa. For $S$. aureus with an absolute signal of 0.3 for the negative control, the MDR value is about $83 \%$.

Safranin Red staining (Fig. 1c, d) led to similar relative standard deviations but lower absolute absorbance values compared to Crystal Violet. This complicates the differentiation from the background and results in higher detection limits of maximal $97.1 \%$ reduction of P. aeruginosa and $92.9 \%$ reduction of $S$. aureus.

Congo Red staining was also tested for biomass quantification, but the absolute absorbance values were too low compared to those of background staining.

The methods of Crystal Violet and Safranin Red led to the same conclusion regarding the effectiveness of the tested cleaners: with cleaner $\mathrm{X}$ among the best while cleaners $\mathrm{C}, \mathrm{D}$, and $\mathrm{E}$ did not remove biofilm efficiently (Fig. 1). In both detection methods, the cleaner treatment did not exhibit an 

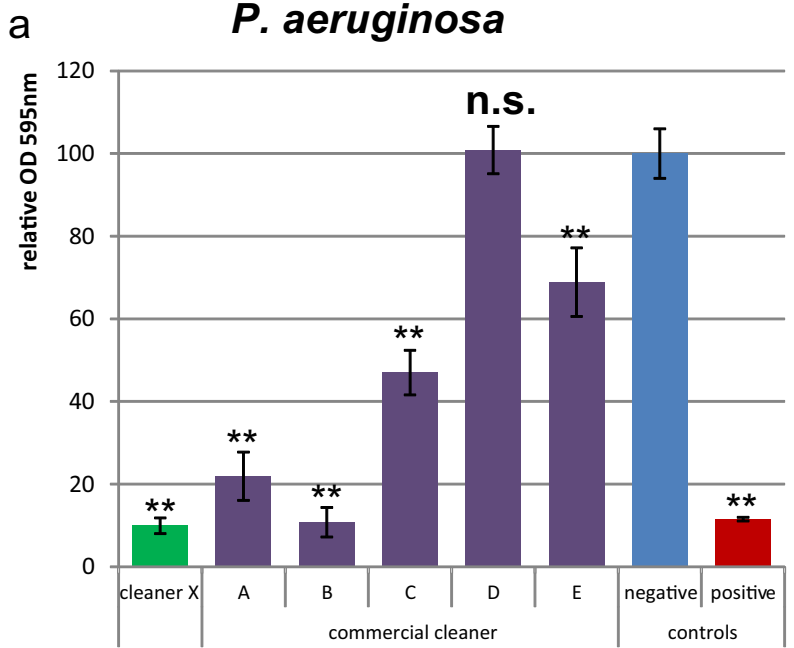

C

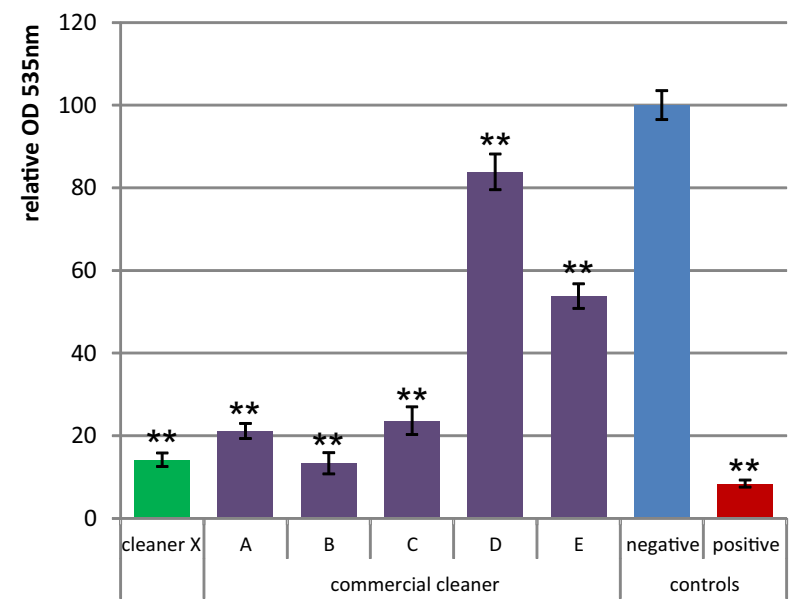

Fig. 1 Total biomass quantification. P. aeruginosa $(\mathbf{a}, \mathbf{c})$ and $S$. aureus (b, d) biofilms were treated with different cleaners. The amount of biofilm was quantified by Crystal Violet $(\mathbf{a}, \mathbf{b})$ and Safranin Red $(\mathbf{c}, \mathbf{d})$ staining. The $Y$-axis represents the biofilm amount relative to the negative control.

effect on the background staining of the wells without bacteria.

\section{Total amount of bacterial cells}

The detection of $P$. aeruginosa cells by SYTO9 (Fig. S3a) did not work sufficiently due to stronger staining of dead cells as described previously (Stiefel et al. 2015). For the detection of S. aureus cells with SYTO9, the ratio of the negative control signal to background noise was higher than that of Crystal Violet (Fig. S3b). According to the MDR value, SYTO9 allowed detection of $99.8 \%$ reduction. However, standard deviations of the wells with bacteria were rather high and reproducibility was low.

For Acridine Orange, the effect of stronger staining of dead cells seemed not to occur and the standard deviations were lower than that for SYTO9 staining (Fig. 2). However, cells b

S. aureus

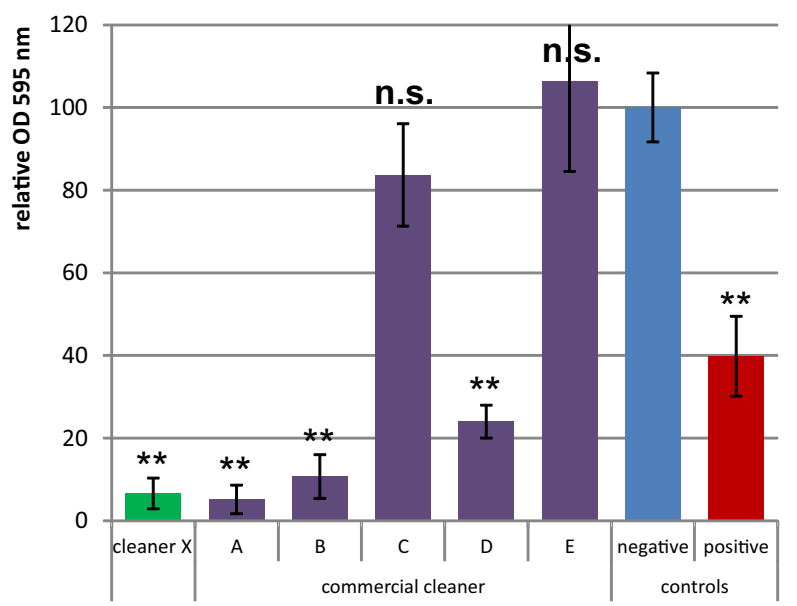

d

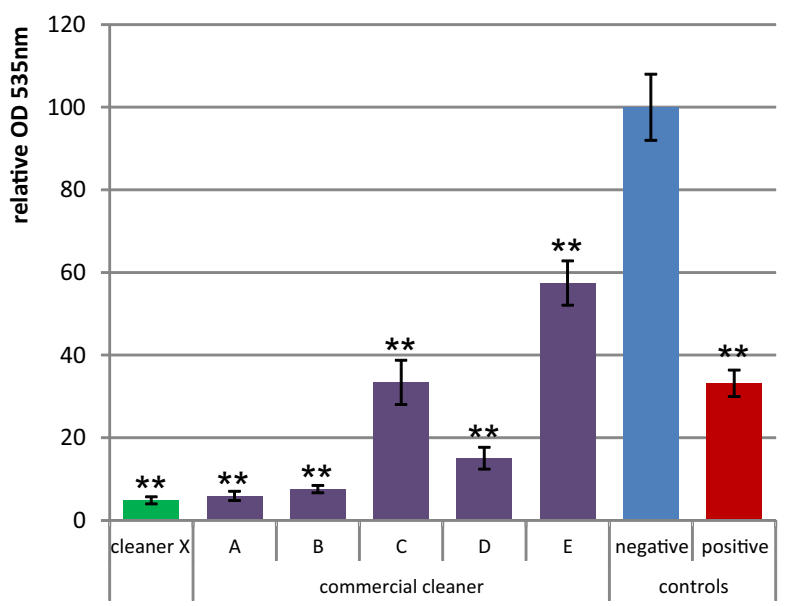

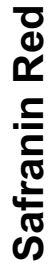

Error bars are generated from six replicas. A $t$ test was applied to each cleaner treatment compared to the negative control to calculate if the differences are statistically highly significant (two asterisks, $p<0.001$ ) or not significant (n.s., $p>0.05$ )

treated with cleaners in general appeared to be stained stronger by Acridine Orange in comparison to cells in control samples.

The results of the SYTO9 and Acridine Orange staining indicated similar differences in the effectiveness of removing bacteria between the tested detergents. Cleaner $\mathrm{X}$ was among the best while cleaners $\mathrm{C}, \mathrm{D}$, and $\mathrm{E}$ did not remove bacteria efficiently (Fig. 2). Cleaner treatment did not have an influence on the binding of the dyes to the plate material as no differences in background fluorescence were observed.

\section{Amount of living bacterial cells}

ATP, which is only produced and retained in living cells, was quantified by BacTiter-Glo ${ }^{\text {TM }}$ Microbial Cell Viability Assay (Fig. 3a, b). This method was very sensitive and displayed a broad linear range. The luminescence signal of the negative control was about 1000 times higher than that of the background of the BacTiter-Glo solution without cells, which 

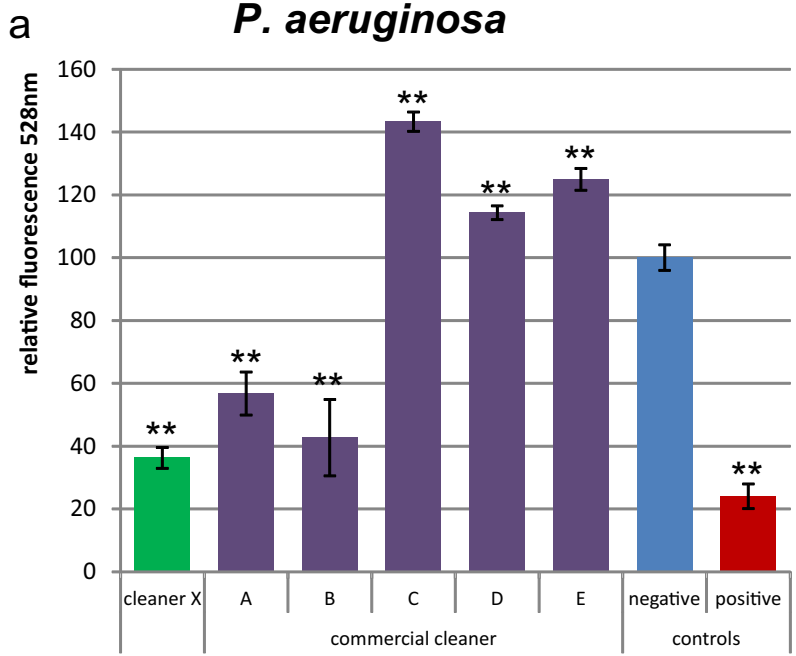

Fig. 2 Total cell quantification by Acridine Orange staining. $P$. aeruginosa (a) and $S$. aureus (b) biofilms were treated with different cleaners. The $Y$-axis represents the fluorescent signal values relative to the negative control. Error bars are generated from six replicas. A $t$ test was b

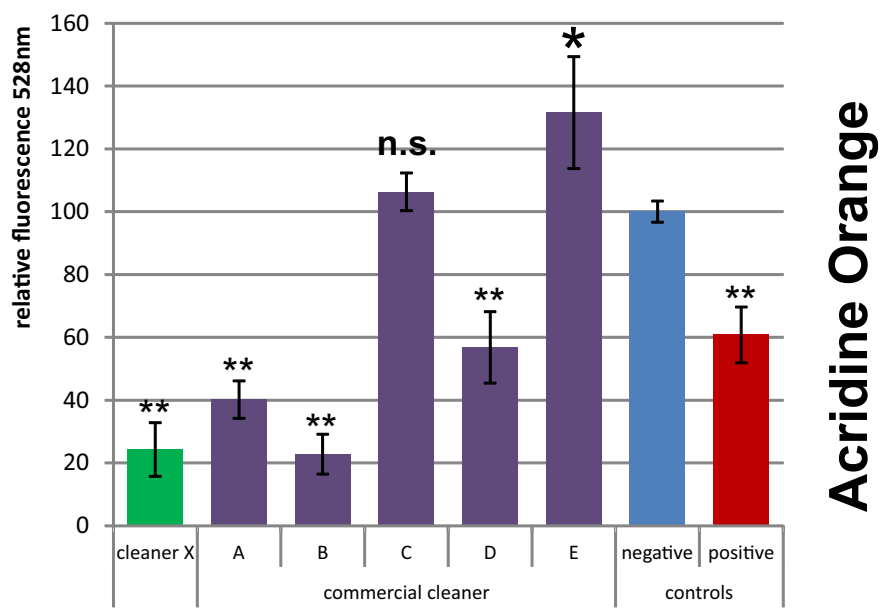

applied to each cleaner treatment compared to the negative control to calculate if the differences are statistically significant (one asterisk, $p<0.05$ ), highly significant (two asterisks, $p<0.001$ ), or not significant (n.s., $p>0.05)$

allows detection of up to 3 Log reductions ( $99.92 \%$ for P. aeruginosa and $99.95 \%$ for $S$. aureus). However, the required materials (e.g., luciferase and luciferin) are expensive, especially for analysis of large numbers of samples.

A cost-efficient alternative to ATP quantification is the turbidity threshold method, in which growth medium is added to the cells after cleaner treatment to measure the time needed to reach a certain optical density (OD) (Fig. S4). The number of remaining viable cells was obtained based on a standard curve (Fig. 3c, d). This method displayed a broad linear range and therefore is very useful for samples with large differences. However, small differences might be difficult to detect because fast-proliferating bacteria result in slight difference of a few minutes in growth. Another disadvantage is the rather long measuring time during which the plate reader is occupied.

A compromise between cost-efficiency and throughput is represented by the use of a tetrazolium salt. Iodonitrotetrazolium (INT) was selected in this study as it forms crystals that stick to the biofilm when converted to formazan. The red-violet formazan crystals were dissolved in DMSO and quantified by absorbance (Fig. S5). In the wells without cells, no formazan was formed and therefore the optical density was not increased in background wells, but the absolute optical density signal for cells treated with the negative control $(0.9 \% \mathrm{NaCl})$ was rather low at only 0.5 , which enables the detection of up to about $2 \mathrm{Log}$ reduction $(99.2 \%$ for $P$. aeruginosa and $99.5 \%$ for $S$. aureus). With higher standard deviation and lower MDR, this method was not as precise and sensitive as the ATP quantification.

Another often used method in viability test is the staining of cells with the fluorescent dyes SYTO9 and propidium iodide (PI), resulting in green fluorescent staining of live cells and red fluorescent staining of dead cells. In the current study,

it was observed that these dyes enabled the quantification of live/dead cells of biofilm in 96-well plates (Fig. S6). One advantage is that total cell and viable cell numbers could be quantified in the same plate by staining first with SYTO9 and subsequently counterstaining with PI. However, as described previously (Stiefel et al. 2015), having the problems with staining gram-negative strains, this method is not always precise for biofilm quantification in 96-well plates. For example, with SYTO9/PI staining, the biofilm treated with cleaner C exhibited higher living cell numbers than those with ATP or turbidity assays. This is likely caused by incomplete replacement of SYTO9 by PI in dead cells, as observed previously (Stiefel et al. 2015), leading to a fallaciously higher number of live cells.

The methods exploited in this work showed that cleaner X was among the best in eliminating viable cells, likely through removing the biofilm based on the results shown in Fig. 1. While all cleaners reduced viable cells of $S$. aureus effectively, cleaners A and B led to more viable cells than the other cleaners. Cleaners D and E did not reduce viable cells of $P$. aeruginosa sufficiently. Very few viable cells were detected after treatment with cleaner $\mathrm{C}$, but an increased background OD at $600 \mathrm{~nm}$ in the turbidity method (Fig. S4a) was observed, indicating that this product contains disinfectant and many dead bacterial cells remain in the well. Similar conclusions regarding the effectiveness of the tested cleaners can be drawn from the ATP assay, turbidity threshold method, and tetrazolium salt method, but not from SYTO9/PI staining.

\section{Biofilm EPS - amount of proteins}

As described previously (Ahmed 2005), many standard protein quantification methods such as the Lowry and BCA 
a

\section{P. aeruginosa}

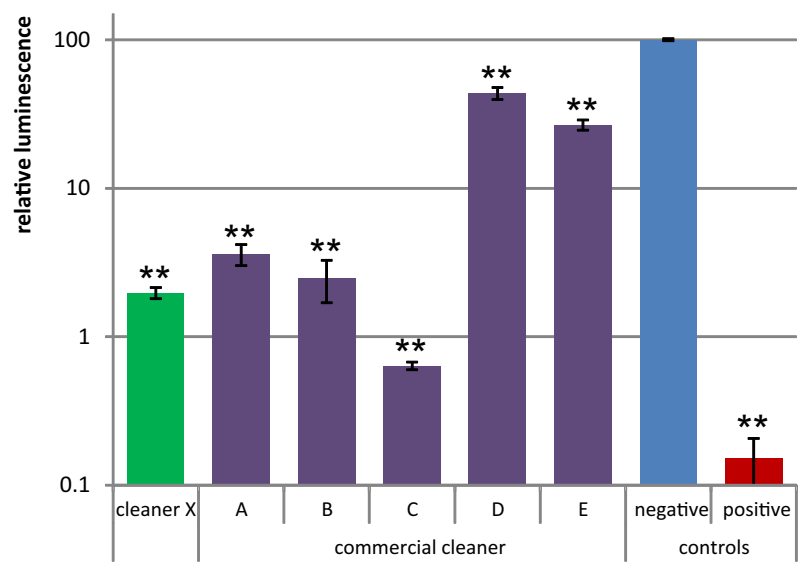

C

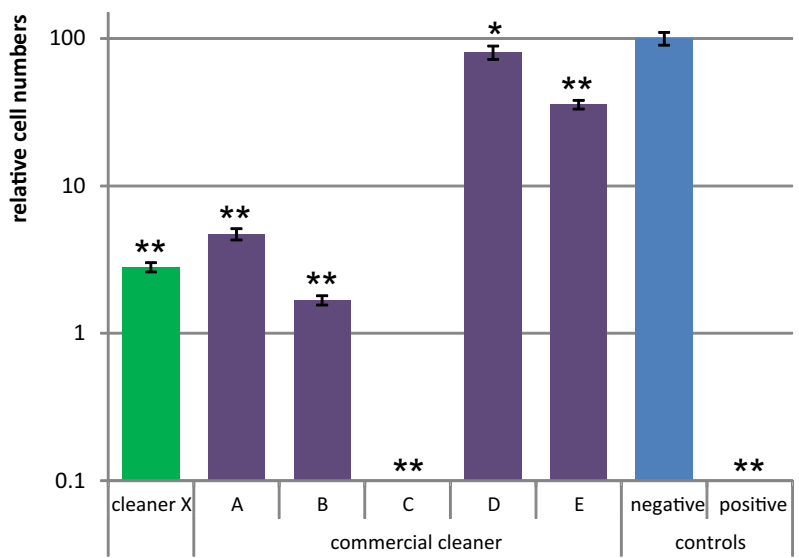

Fig. 3 Quantification of viable cells. P. aeruginosa (a, c) and $S$. aureus (b, d) biofilms were treated with different cleaners. The viable cells were quantified by ATP detection with BacTiter-Glo reagent (a, b) and regrowth in the Turbidity Threshold method $(\mathbf{c}, \mathbf{d})$. The $Y$-axis represents the cell numbers relative to the negative control. Error bars are generated

assays did not work properly in the complex environment of biofilm. Often, reducing agents (e.g., most sugars) and other components of the biofilm generate wrong signals, especially if treated with cleaners. In this study, it was found that staining methods such as CBQCA and NanoOrange were influenced by the antecedent cleaner treatment and not further investigated (data not shown). SYPRO Ruby was found to have a high affinity for the plate material (both polystyrene and polypropylene), resulting in high background (Table 2).

A simple but promising method is the staining with fluorescein isothiocyanate (FITC) (Fig. 4). The background staining of the wells without cells was rather high, but not influenced by the cleaner treatment. The signal of the negative control was only seven times higher than the background staining, and standard deviations of the background were rather high, resulting in a MDR value of $91.8 \%$ for $P$. aeruginosa b

\section{S. aureus}

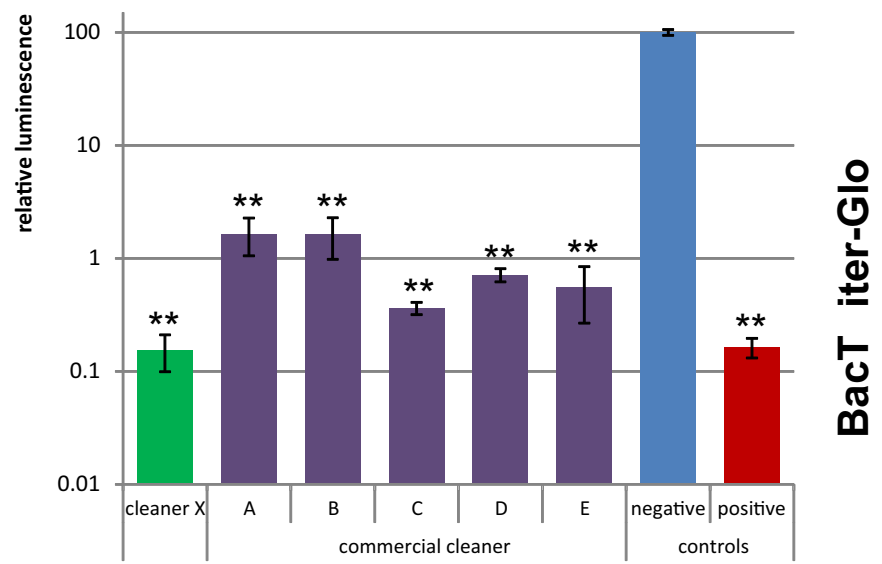

d
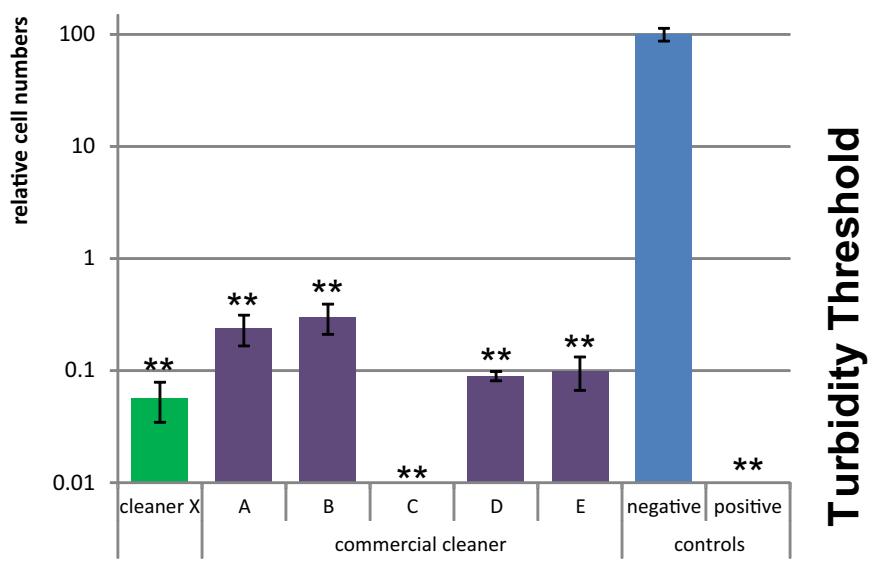

from six replicas. A $t$ test was applied to each cleaner treatment compared to the negative control to calculate if the differences are statistically significant (one asterisk, $p<0.05$ ) or highly significant (two asterisks, $p<0.001$ )

and $91.2 \%$ for $S$. aureus. However, the standard deviations for low values were small and should allow detection of up to $95 \%$ reduction. The quantified protein level for some cleaners (e.g., cleaner C) was too high compared to that of the negative control. This might be explained by the possibility that the detergents modified the proteins, which consequently influenced protein binding to FITC. This effect is unlikely caused by residual detergents on the plate as the background staining in empty wells was not affected.

The results of the FITC staining demonstrate that cleaner X was among the best in removing EPS proteins, while cleaners $\mathrm{C}$, D, and $\mathrm{E}$ did not remove proteins effectively. These results led to the same conclusion regarding the effectiveness of the tested cleaners as those with methods targeting biomass and total bacteria, indicating that the method is suitable for EPS protein quantification in the 96-well plate system. 
Table 2 Summary and evaluation of the performance of different detection methods

\begin{tabular}{|c|c|c|c|c|c|c|c|c|}
\hline \multirow[t]{2}{*}{ Target } & \multirow[t]{2}{*}{ Method } & \multirow{2}{*}{$\begin{array}{l}\text { BG } \\
\pm S D\end{array}$} & \multicolumn{2}{|c|}{ P. aeruginosa } & \multicolumn{2}{|c|}{ S. aureus } & \multirow[t]{2}{*}{ Advantages } & \multirow[t]{2}{*}{ Disadvantages } \\
\hline & & & SNC & MDR & SNC & MDR & & \\
\hline \multirow[t]{3}{*}{$\begin{array}{l}\text { Total } \\
\text { Biomass }\end{array}$} & Crystal Violet & $\begin{array}{r}0.05 \\
\pm 0.004\end{array}$ & 1 & $98.7 \%$ & 0.3 & $95.2 \%$ & $\begin{array}{l}\text { precise for quantification of high amount of } \\
\text { biofilm, easy optical control }\end{array}$ & rather high detection limit \\
\hline & Safranin Red & $\begin{array}{r}0.04 \\
\pm 0.005 \\
\end{array}$ & 0.55 & $97.1 \%$ & 0.25 & $92.9 \%$ & similar to Crystal Violet & lower absolute signal than $\mathrm{CV}$ \\
\hline & Congo Red & $\begin{array}{r}0.04 \\
\pm 0.006 \\
\end{array}$ & 0.25 & $91.4 \%$ & 0.1 & $70.0 \%$ & & signal too low to distinguish from background \\
\hline \multirow{2}{*}{$\begin{array}{l}\text { Total } \\
\text { bacterial } \\
\text { cells }\end{array}$} & SYT09 & $\begin{array}{l}350 \\
\pm 14\end{array}$ & $2^{\prime} 000$ & $97.5 \%$ & $18^{\prime} 000$ & $99.8 \%$ & $\begin{array}{l}\text { small standard deviation, no washing step } \\
\text { required }\end{array}$ & $\begin{array}{l}\text { linear only in a narrow range, expensive, not } \\
\text { accurate for some bacteria (viable Gram-negative) }\end{array}$ \\
\hline & $\begin{array}{l}\text { Acridine } \\
\text { Orange }\end{array}$ & $\begin{array}{l}200 \\
\pm 27\end{array}$ & $2^{\prime} 000$ & $95.5 \%$ & $1^{\prime} 600$ & $94.2 \%$ & $\begin{array}{l}\text { less expensive than SYTO9, sensitive, small } \\
\text { standard deviation }\end{array}$ & $\begin{array}{l}\text { unbound dye has to be washed off, slightly } \\
\text { increased signal by detergent treatment }\end{array}$ \\
\hline \multirow{4}{*}{$\begin{array}{l}\text { Viable } \\
\text { bacterial } \\
\text { cells }\end{array}$} & BacTiter & $\begin{array}{l}2^{\prime} 500 \\
\pm 450\end{array}$ & $1^{\prime} 600^{\prime} 000$ & $99.92 \%$ & $2^{\prime} 500^{\prime} 000$ & $99.95 \%$ & $\begin{array}{l}\text { very precise, very sensitive, broad linear } \\
\text { range }\end{array}$ & very expensive, luminescent plate reader needed \\
\hline & $\begin{array}{l}\text { Turbidity } \\
\text { (cell numbers) }\end{array}$ & $<10^{4}$ & $4 * 10^{7}$ & $>99.9 \%$ & $1 * 10^{8}$ & $>99.99 \%$ & $\begin{array}{l}\text { broad linear range, useful for low cell } \\
\text { numbers, cheap }\end{array}$ & $\begin{array}{l}\text { only one plate per day, not accurate for small } \\
\text { differences }\end{array}$ \\
\hline & INT & $\begin{array}{l}<0.001 \\
\pm 0.001\end{array}$ & 0.36 & $99.2 \%$ & 0.62 & $99.5 \%$ & $\begin{array}{l}\text { cheaper than BacTiter-Glo and higher } \\
\text { throughput than Turbidity assay }\end{array}$ & $\begin{array}{l}\text { lower sensitivity than BacTiter-Glo and Turbidity } \\
\text { assay }\end{array}$ \\
\hline & SYT09/PI & $\begin{array}{l}350 \\
\pm 14\end{array}$ & $2^{\prime} 000$ & $97.5 \%$ & $18^{\prime} 000$ & $99.8 \%$ & $\begin{array}{l}\text { small standard deviation, no washing step } \\
\text { required }\end{array}$ & $\begin{array}{l}\text { linear only in a narrow range, expensive, not } \\
\text { working properly for some bacteria (mainly Gram- } \\
\text { negative) }\end{array}$ \\
\hline \multirow[t]{2}{*}{ Proteins } & FITC & $\begin{array}{l}240 \\
\pm 40\end{array}$ & $1^{\prime} 700$ & $91.8 \%$ & $1^{\prime} 600$ & $91.2 \%$ & small standard deviation, easy to handle & $\begin{array}{l}\text { high detection limits, results affected by some } \\
\text { detergents }\end{array}$ \\
\hline & SYPRO Ruby & $\begin{array}{l}900 \\
\pm 60\end{array}$ & 850 & 0 & 350 & 0 & - & $\begin{array}{l}\text { higher signal in empty wells and media controls } \\
\text { than in wells containing bacteria }\end{array}$ \\
\hline \multirow[t]{2}{*}{$\begin{array}{l}\text { Polysac- } \\
\text { charids }\end{array}$} & $\begin{array}{l}\text { Calcofluor } \\
\text { White }\end{array}$ & $\begin{array}{l}24^{\prime} 000 \\
\pm 1000\end{array}$ & $20^{\prime} 000$ & 0 & $16^{\prime} 000$ & 0 & - & $\begin{array}{l}\text { higher signal in empty wells and media controls } \\
\text { than in wells containing bacteria, some detergents } \\
\text { influence the staining }\end{array}$ \\
\hline & ConA-FITC & $\begin{array}{l}300 \\
\pm 40\end{array}$ & 400 & 0 & 150 & 0 & - & Not sensitive enough \\
\hline
\end{tabular}

Biofilm formed at $33^{\circ} \mathrm{C}$ and $40 \mathrm{rpm}$ for $24 \mathrm{~h}$ was quantified by the different methods as described in Materials and methods. Signals are measured by absorbance (green), fluorescence (orange), or luminescence (blue). Absolute signals of biofilm treated with $0.9 \% \mathrm{NaCl}$ (SNC - negative control) are compared with the background signal from wells without bacteria (BG) and the standard deviation of the background (SD). The maximal detectable reduction (MDR) value reflects the detection limits which should be distinguishable from noise of BG

\section{Biofilm EPS - amount of polysaccharides}

ConA-FITC and Calcofluor White showed a high affinity toward the plate material (both polystyrene and polypropylene) resulting in high background, which makes it difficult to distinguish the biofilm signal from the background signal (Table 2). Other methods often used for sugar quantification, such as the phenol-sulfuric acid method (Dubois et al. 1951), were not sensitive enough to quantify polysaccharides of biofilm in the microplate system and not further investigated (data not shown).

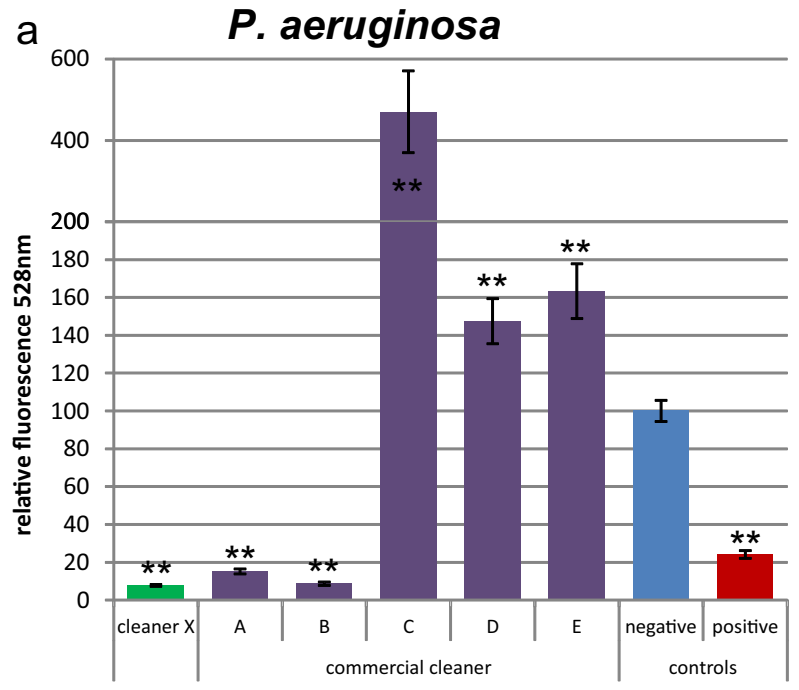

Fig. 4 Quantification of biofilm protein by FITC staining. P. aeruginosa (a) and $S$. aureus (b) biofilms were treated with different cleaners. The $Y$-axis represents the fluorescent signal values relative to the negative control. Error bars are generated from six replicas. A $t$ test was applied

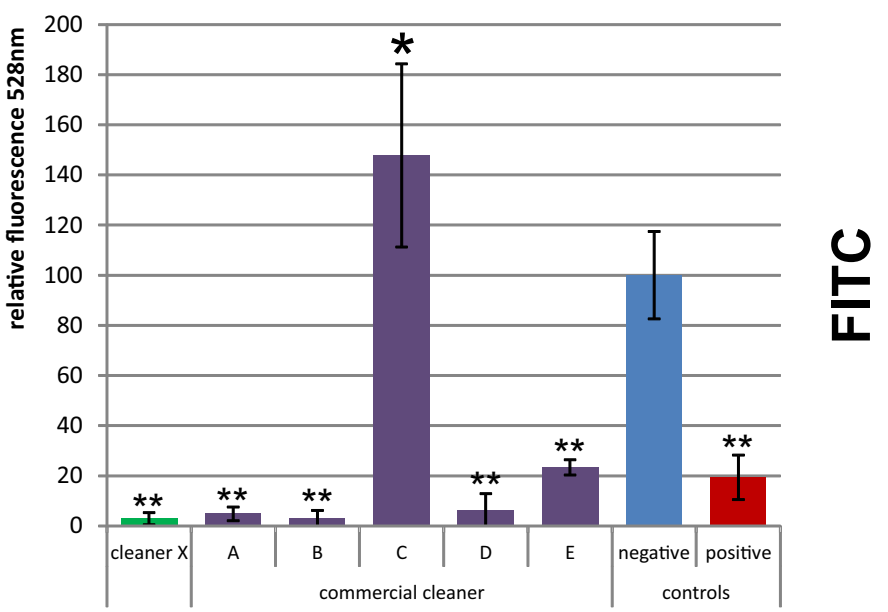

to each cleaner treatment compared to the negative control to calculate if the differences are statistically significant (one asterisk, $p<0.05$ ) or highly significant (two asterisks, $p<0.001$ ) 


\section{Discussion}

Different methods were applied and compared, using biofilm removal with cleaners as a case study for biofilm quantification. Methods detecting total biomass such as Crystal Violet reveal how much biofilm is present. Approaches for viability detection such as the BacTiter-Glo assay and turbidity threshold method indicate how many living bacterial cells are remaining. Only when the methods for total biofilm assay and viability assay are combined can it be revealed if bacteria are removed or only killed. Quantification methods for EPS components give an insight in how much of the biofilm matrix is removed and thereby reveal the removal of the enzyme targets. However, such methods are difficult to perform in 96well plates due to low sensitivity or high background. A screening for different fluorescently labeled lectins could help to identify more sensitive staining of polysaccharide. Taking into account that most protein and polysaccharide quantification methods are not able to differentiate between EPS and cell membrane compounds such as peptidoglycan and LPS, it is anyway difficult to quantify the EPS alone. Nevertheless, with the knowledge of total biomass in comparison with bacteria quantification, estimations can be made on the amount of EPS.

In the case of biofilm cleaning, the most important parameters for cleaning efficiency are total biomass and living bacterial cells. The presence of viable cells will enable fast recolonization if enough nutrients are available. When an inefficient cleaner with disinfection properties is used, nutrients could be derived from dead bacterial cells and EPS and further used for bacterial adhesion and proliferation (Finkel and Kolter 2001). The different methods used here allowed detailed investigation of the cleaners regarding their killing and removing performance. It was observed that cleaner $\mathrm{C}$ did not remove $S$. aureus biofilm based on $\mathrm{CV}$ and Acridine Orange staining (Figs. $1 b$ and $2 b$ ), but led to almost no viable cells detected by the BacTiter-Glo assay and turbidity method (Fig. 3b, d). Only the results of both total biomass and viability assays allowed the conclusion that cleaner $\mathrm{C}$ rather killed and fixed bacterial cells than removing the biofilm.

The performance of different cleaners in biofilm removal is summarized in Table 1. Cleaners A and B removed bacteria and EPS of both species efficiently, and did not kill the bacteria. Cleaner $\mathrm{C}$ partially removed $P$. aeruginosa but did not remove $S$. aureus. However, it killed both species effectively. Cleaner D partially removed $S$. aureus but neither removed nor killed $P$. aeruginosa. Cleaner E did not remove any of the two species but killed $S$. aureus. The novel cleaner X efficiently removed biofilm of both species and was only slightly biocidal.

In this study, 13 different assays which target different parts of biofilm were conducted and compared in a microplate model. The advantages and disadvantages of the tested methods are summarized in Table 2. It can be concluded that different methods are required to determine if a cleaner kills or removes biofilm. Depending on the target, it is important to choose the correct quantification method. For disinfectants, it is necessary to quantify cell viability. However, if removal of biofilm is the objective, methods which quantify total biomass or specific compounds of the biofilm should be applied. The combination of BacTiter-Glo assay and CV staining was found to be particularly suitable to investigate if a product rather acts as a disinfectant or cleaner.

Acknowledgments We thank Stefanie Altenried for help with performing the experiments. This study was funded by the Swiss Federal Commission for Technology and Innovation (CTI) grant Nr. 15429.1 PFLS-LS.

\section{Compliance with ethical standards}

Competing interests The authors declare that they have no conflict of interest.

Ethical statement This article does not contain any studies with human participants performed by any of the authors.

Open Access This article is distributed under the terms of the Creative Commons Attribution 4.0 International License (http:// creativecommons.org/licenses/by/4.0/), which permits unrestricted use, distribution, and reproduction in any medium, provided you give appropriate credit to the original author(s) and the source, provide a link to the Creative Commons license, and indicate if changes were made.

\section{References}

Ahmed H (2005) Principles and reactions of protein extraction, purification, and characterization. CRC Press, Boca Raton

Alfa MJ, Degagne P, Olson N (1999) Worst-case soiling levels for patient-used flexible endoscopes before and after cleaning. Am J Infect Control 27(5):392-401

Alt V, Bechert T, Steinrucke P, Wagener M, Seidel P, Dingeldein E, Domann E, Schnettler R (2004) In vitro testing of antimicrobial activity of bone cement. Antimicrob Agents Chemother 48(11): $4084-4088$

Berney M, Vital M, Hulshoff I, Weilenmann HU, Egli T, Hammes F (2008) Rapid, cultivation-independent assessment of microbial viability in drinking water. Water Res 42(14):4010-4018

Chen MY, Lee DJ, Tay JH, Show KY (2007) Staining of extracellular polymeric substances and cells in bioaggregates. Appl Microbiol Biotechnol 75(2):467-474

Chiu KW, Tsai MC, Wu KL, Chiu YC, Lin MT, Hu TH (2012) Surveillance cultures of samples obtained from biopsy channels and automated endoscope reprocessors after high-level disinfection of gastrointestinal endoscopes. BMC Gastroenterol 12:120

Cochran WL, McFeters GA, Stewart PS (2000) Reduced susceptibility of thin Pseudomonas aeruginosa biofilms to hydrogen peroxide and monochloramine. J Appl Microbiol 88(1):22-30 
Dubois M, Gilles K, Hamilton JK, Rebers PA, Smith F (1951) A colorimetric method for the determination of sugars. Nature 168(4265): 167

Elasri MO, Miller RV (1999) Study of the response of a biofilm bacterial community to UV radiation. Appl Environ Microbiol 65(5):20252031

Finkel SE, Kolter R (2001) DNA as a nutrient: novel role for bacterial competence gene homologs. J Bacteriol 183(21):6288-6293

Flemming HC, Wingender J (2001) Relevance of microbial extracellular polymeric substances (EPSs) - part I: structural and ecological aspects. Water Sci Technol 43(6):1-8

Hadi R, Vickery K, Deva A, Charlton T (2010) Biofilm removal by medical device cleaners: comparison of two bioreactor detection assays. J Hosp Infect 74(2):160-167

Hatzinger PB, Palmer P, Smith RL, Penarrieta CT, Yoshinari T (2003) Applicability of tetrazolium salts for the measurement of respiratory activity and viability of groundwater bacteria. J Microbiol Methods 52(1):47-58

Kovaleva J, Peters FT, van der Mei HC, Degener JE (2013) Transmission of infection by flexible gastrointestinal endoscopy and bronchoscopy. Clin Microbiol Rev 26(2):231-254

O’Toole GA (2011) Microtiter dish biofilm formation assay. J Vis Exp 47

Pajkos A, Vickery K, Cossart Y (2004) Is biofilm accumulation on endoscope tubing a contributor to the failure of cleaning and decontamination? J Hosp Infect 58(3):224-229

Palestrant D, Holzknecht ZE, Collins BH, Parker W, Miller SE, Bollinger RR (2004) Microbial biofilms in the gut: visualization by electron microscopy and by acridine orange staining. Ultrastruct Pathol 28(1):23-27

Pantanella F, Valenti P, Natalizi T, Passeri D, Berlutti F (2013) Analytical techniques to study microbial biofilm on abiotic surfaces: pros and cons of the main techniques currently in use. Ann Ig 25(1):31-42

Patterson JL, Stull-Lane A, Girerd PH, Jefferson KK (2010) Analysis of adherence, biofilm formation and cytotoxicity suggests a greater virulence potential of Gardnerella vaginalis relative to other bacterial-vaginosis-associated anaerobes. Microbiology 156(Pt 2): 392-399

Peeters E, Nelis HJ, Coenye T (2008) Comparison of multiple methods for quantification of microbial biofilms grown in microtiter plates. $\mathrm{J}$ Microbiol Methods 72(2):157-165

Pendleton JN, Gorman SP, Gilmore BF (2013) Clinical relevance of the ESKAPE pathogens. Expert Rev Anti-Infect Ther 11(3): 297-308

Pitts B, Hamilton MA, Zelver N, Stewart PS (2003) A microtiter-plate screening method for biofilm disinfection and removal. J Microbiol Methods 54(2):269-276

Stepanovic S, Vukovic D, Dakic I, Savic B, Svabic-Vlahovic M (2000) A modified microtiter-plate test for quantification of staphylococcal biofilm formation. J Microbiol Methods 40(2):175-179

Stewart PS, Costerton JW (2001) Antibiotic resistance of bacteria in biofilms. Lancet 358(9276):135-138

Stiefel P, Schmidt-Emrich S, Maniura-Weber K, Ren Q (2015) Critical aspects of using bacterial cell viability assays with the fluorophores SYTO9 and propidium iodide. BMC Microbiol 15(1):36

Sutherland IW (2001) The biofilm matrix — an immobilized but dynamic microbial environment. Trends Microbiol 9(5):222-227

Tawakoli PN, Al-Ahmad A, Hoth-Hannig W, Hannig M, Hannig C (2013) Comparison of different live/dead stainings for detection and quantification of adherent microorganisms in the initial oral biofilm. Clin Oral Investig 17(3):841-850

Vickery K, Pajkos A, Cossart Y (2004) Removal of biofilm from endoscopes: evaluation of detergent efficiency. Am J Infect Control 32(3):170-176

Zimlichman E, Henderson D, Tamir O, Franz C, Song P, Yamin CK, Keohane C, Denham CR, Bates DW (2013) Health careassociated infections: a meta-analysis of costs and financial impact on the US health care system. JAMA Intern Med 173(22):2039-2046 